\title{
Uma Experiência de Inclusão através das Artes e das Tecnologias Digitais
}

\author{
Ana Vilma Tijiboy * \\ Rosa Maria Casaccia** \\ Rejane Dias Carpin ${ }^{* * *}$
}

\section{Resumo}

O presente trabalho relata uma experiência de aprendizagem cooperativa em artes e tecnologias digitais, desenvolvida com Pessoas com Necessidades Educacionais Especiais. As estratégias pedagógicas, artísticas e de interação que foram utilizadas, são aqui apresentadas assim como constatações importantes surgidas no processo de realização da experiência. Reflexões e descobertas são compartilhadas na tentativa de incentivar outros profissionais a proporem ações similares ou mais ousadas junto a esta parcela da população .

Palavras-chave: inclusão digital, pessoas com necessidades educacionais especiais, inclusão social.

\begin{abstract}
This article presents an experience developed under a cooperative learning perspective in which people with special educational needs and digital technology are brought together. The educational, artistic and interaction strategies of interaction used are here presented as well as important episodes and findings during the experience. Reflections and findings are shared with the readers as an attempt to incentive other teachers and professionals to propose similar or even more challenging actions involving this population.
\end{abstract}

Keywords: digital inclusion, people with special educational needs, social inclusion

\footnotetext{
${ }^{1}$ Dra. Em Informática na Educação, Mestre em Educação e Socióloga, atuando no NAPNES/ET/UFRGS como pesquisadora e coordenadora de projetos e cursos. Coordenadora do Setor de Apoio a Alunos com Deficiência Visual da UFRGS. anatiii@etcom.ufrgs.br

"“Professora de Artes Plásticas, membro da ONG Cristal Florido. rosacasaccia@hotmail.com

*** Especialista em Educação de Surdos, professora de surdos na Escola Lilia Mazeron, interprete de LIBRAS e voluntária no NAPNES/ET/UFRGS. 44mare@gmail.com
} 


\section{Introdução}

A criação de novos espaços sociais e educacionais de aprendizagem para Pessoas com Necessidades Educacionais Especiais (PNEEs), permeados por desafios para o encontro de soluções criativas a problemas ou situações propostas, vem sendo, nos últimos anos, uma tendência por parte de educadores e pesquisadores engajados com a inclusão. Estes ambientes devem privilegiar o incentivo ao trabalho cooperativo, a criação e reflexão não apenas de conteúdos ou áreas de conhecimentos específicos, mas de questões pessoais e sociais mais abrangentes e relevantes para a vida.

Acredita-se que estes esforços, além de possibilitarem a descoberta de potencialidades dos participantes por eles mesmos e pelos que convivem com eles, contribuem, também, para transformar a percepção negativa que a sociedade tem sobre eles. Contestar esse imaginário social de menos capacidade, fruto do paradigma clínico-terapêutico ainda tão marcante na Educação Especial, vem sendo um dos objetivos explícitos de alguns projetos educacionais.

A experiência aqui relatada sintoniza com essa tendência que se opõe à rotulação social de inferioridade das capacidades destas pessoas, que não aceitando o futuro clínico ou o que Wellendorf (citado por Beyer, 2005) chamam de "carreira clínica" destinada a essa população.

\section{A Experiência}

A experiência desenvolveu-se sob o nome Projeto: Animação Stopmotion com Massinhas de Modelar por Pessoas com Necessidades Especiais e ocorreu nas dependências do Núcleo de Pesquisa e Apoio a Pessoas com Necessidades Educacionais Especiais (NAPNES/ET/UFRGS). Ela se situa dentro dos projetos da Redejovempaz ${ }^{2}$ a qual visa à criação e ao estudo de experiências educativas desequilibradoras em rede que contribuam aos processos de complexificação de indivíduos e grupos, integrando redes de interação presenciais e à distância.

Acredita-se ser esta experiência uma ação inclusiva através por meio de duas vias. A primeira, dando acesso a novos saberes através das tecnologias e artes a pessoas com necessidades especiais e incentivando seu papel de atores e de expressão criativa. A segunda, divulgando junto à sociedade 0 potencial que a realização da experiência desvela. Neste cenário, recursos como a web constituem-se em aliados importantes e retomam seu papel social.

Nesse contexto, nosso objetivo era o de aproximar adolescentes e adultos com necessidades especiais às tecnologias digitais ${ }^{3}$, recursos por eles desconhecidos até então, e ao nosso ver recursos capazes de promover o potencial criativo, de expressão, de auto-conhecimento e de que conferir àqueles que as dominam um alto reconhecimento social, contribuindo, neste caso, para desmistificação de concepções equivocadas quanto à incapacidade atribuída às pessoas com necessidades educacionais especiais. Uma das

http://redejovempaz.cap.ufrgs.br/exibebusca.php

${ }^{3}$ Meios de informação e comunicação em geral - câmara digital, scanner, computador, internet.

$2 \longrightarrow$ V. $4 \mathrm{~N}^{\circ}$ 1, Julho, 2006 
premissas básicas que nos apoiavam, já comprovadas em outros estudos (Tijiboy, 2003), era de que PNEEs, ao se apropriarem de tecnologia de ponta como a informática, passam a ser vistos com um status social mais elevado e positivo que quando não possuíam tal domínio tecnológico.

O desafio proposto ao grupo foi o de realizar um filme de animação através das artes plásticas e da utilização de tecnologias digitais. Isso representava para os participantes a aprendizagem de novas linguagens de expressão e a exploração e apropriação de novas áreas de conhecimento. Cabe lembrar, o quanto ambientes desafiadores podem promover a aprendizagem em qualquer pessoa, o que nos faz refletir sobre a relevância ainda maior que tais ambientes adquirem quando se trata de PNEEs, a quem é oferecido ainda apenas o que as concepções ideológicas/pedagógicas medievais (Skliar, 2004) propunham.

Assim, estas pessoas ao invés de jogarem, repetem, em vez de moverem-se, exercitam-se, ocupando um papel passivo e de imitação, de prática, de copia e de seguidores dos "normais". Raramente lhes são permitidos ou incentivados, nos diversos espaços sociais papeis mais ativos e de criação.

Concretamente, os participantes da experiência aprenderam a técnica de stop-motion utilizando massinhas de modelar, câmera digital e computador. Stop-motion é uma técnica de animação na qual se cria a ilusão de movimento através de fotografias quadro a quadro. A cada foto tirada, mudam-se as posições dos objetos e/ou personagens, criando uma ilusão ótica de ação, de movimento. Assim, pequenos filmes são criados, juntando-se todas as fotos com o uso de Flash ou de outros programas computacionais. Filmes comerciais como A Fuga das Galinhas e Guerra nas Estrelas, são exemplos de utilização de tal técnica.

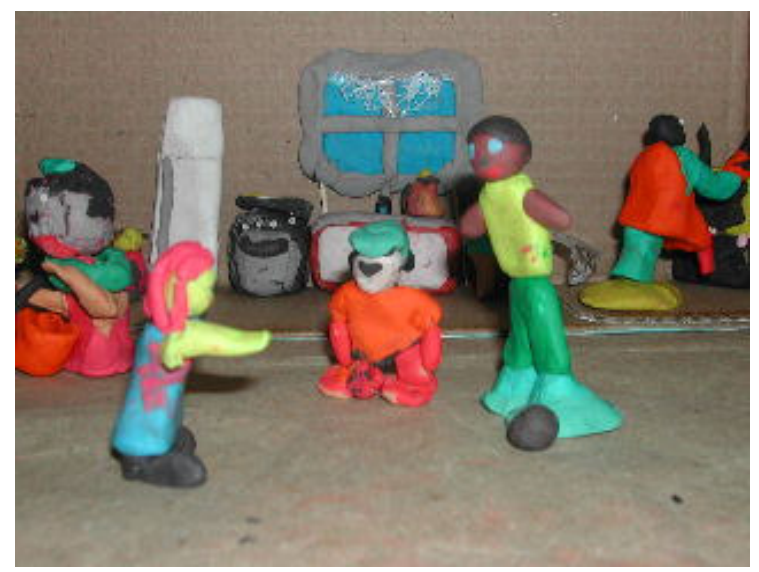

Figura 1 - Parte do cenário do filme. 


\section{Etapas e Estratégias Utilizadas}

O projeto foi planejado para ser desenvolvido em duas etapas. $\mathrm{Na}$ primeira, os jovens aprenderam a utilizar a câmara digital para a tomada das imagens que foram juntadas por um deles, posteriormente, com o programa computacional flash.

Assim, o caminho percorrido no desenvolvimento desta primeira etapa envolveu as seguintes estratégias:

- sessão de cinema com projeção de filmes de animação stop motion, como forma de motivação inicial;

- manipulação de objetos miniaturas trazidos pelos alunos;

- manuseio e exploração de massinhas de modelar por parte dos alunos;

- elaboração de roteiro em atividades cooperativas;

- criação de personagens modelados em massinhas de modelar a partir do roteiro elaborado;

- montagem de cenário e objetos cênicos com diversos materiais tais como: papel, papelão, miçangas, glitter, purpurina, lantejoulas, palito de dentes, cola, papel de bala, fios;

- situações de interação em grupos envolvendo pessoas com outras necessidades especiais: surdos, com paralisia cerebral e com deficiência mental;

- incentivo à observação e à reflexão na construção de conceitos novos;

- trocas de experiências com alunos de escolas de ensino regular que visitaram o projeto;

- edição do filme utilizando software flash 5.0 por jovem com paralisia cerebral;

- discussões sobre assuntos surgidos no grupo e de seu interesse, como por exemplo, a discriminação de setores populacionais representados pelos participantes: deficientes físicos, idosos, estrangeiros, surdos e negros; - investigação via web de sites relacionados a cinema de animação, make off de filmes para posterior confecção de páginas web sobre o projeto;

- divulgação do projeto no meio acadêmico;

- apresentação do produto final (filme de animação) para pessoas da comunidade universitária e externa;

- interação síncrona via chat com colegas virtuais da RedejovemPaz.

A segunda etapa envolverá o relato da experiência, através da confecção de páginas web e colocação das mesmas na Internet. Espera-se, assim, compartilhar com outros e estabelecer parcerias que surjam com tal divulgação. Ao mesmo tempo, espera-se com a divulgação do trabalho, a promoção de reflexões e mudanças de concepções sobre a interação com 
Pessoas com Necessidades Educacionais Especiais, por parte dos internautas que venham tomar conhecimento do projeto.

\section{Os Participantes}

Fizeram parte do projeto: um jovem adulto com paralisia cerebral, seis jovens surdos e uma jovem-adulta com deficiência mental. A faixa etária variou entre 14 e 25 anos de idade e todos cursavam o ensino fundamental. A equipe dos facilitadores, por sua vez, foi composta por uma professora de artes, uma pesquisadora na área de informática na educação especial e uma interprete de Língua Brasileira de Sinais (LIBRAS) que também é professora de alunos surdos.

Para a realização da experiência estabeleceu-se uma parceria envolvendo: a ONG Associação Cristal Florido, a Universidade Federal do Rio Grande do Sul através do Núcleo de Pesquisa e Atendimento a Pessoas com Necessidades Especiais (NAPNES) e a Escola Estadual de Ensino Fundamental Professora Lilia Mazeron, escola especial de surdos.

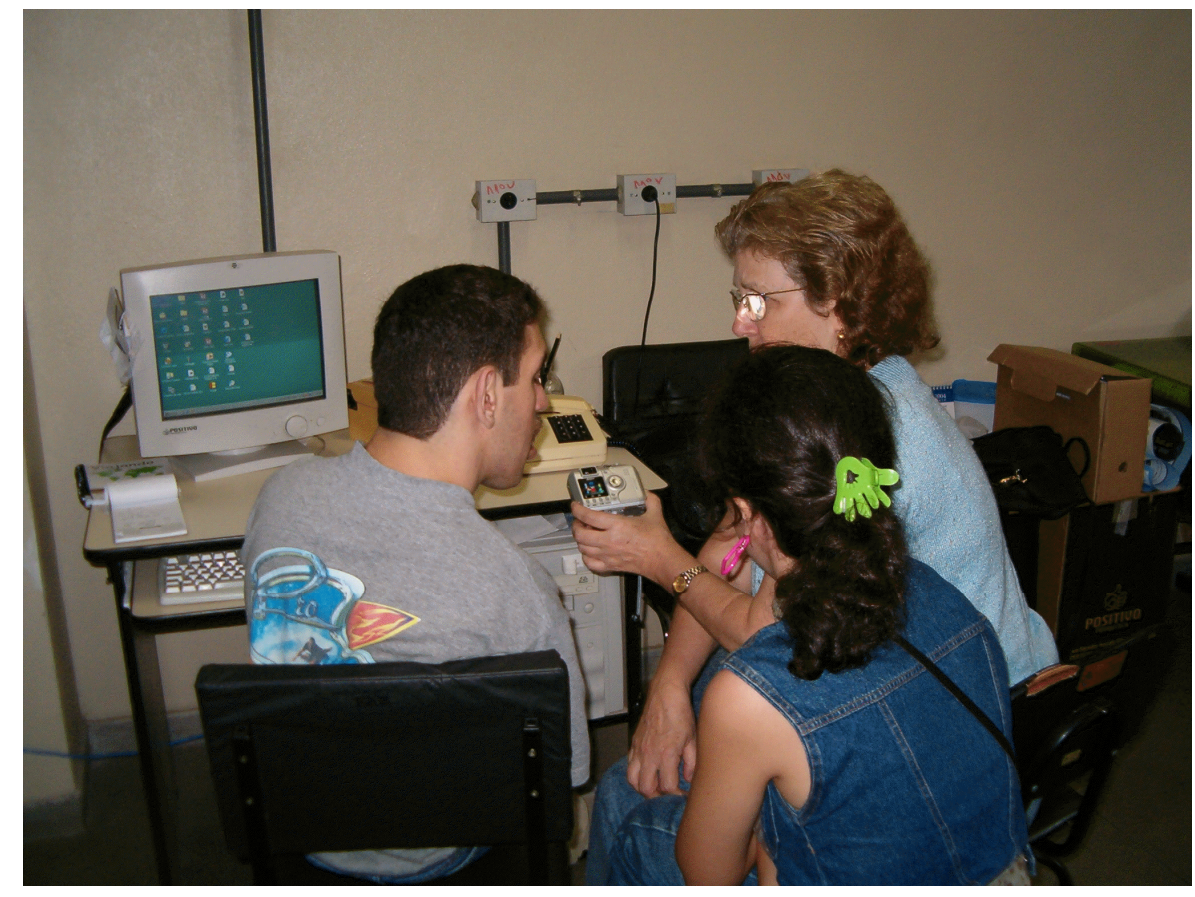

Figura 2 - Aprendizagem de flash e câmara digital - aluno com paralisia cerebral 


\section{Constatações}

A riqueza de descobertas e aprendizagens pessoais, sociais e pedagógicas foi uma constante no decorrer da experiência e constitui-se em um dos pontos a serem ressaltados.

Um aspecto observado foram as atitudes e competências de trabalho cooperativo e a capacidade de síntese. A esse respeito, cabe mencionar a dificuldade inicial dos surdos no trabalho em grupo, que não conseguiam descentrar-se de suas construções individuais na atividade de criação da história coletiva que seria o enredo do filme. Em contraste a esse comportamento, destacou-se a capacidade de síntese do aluno com paralisia cerebral ao incorporar partes das historias individuais em uma única história, que acabou sendo a história final do grupo.

Dentre as aprendizagens, cabe citar a descoberta e autodescoberta de habilidades motoras ligadas à motricidade fina ainda desconhecidas pelo próprio jovem com paralisia cerebral e pela equipe, reveladas na atividade de confecção do cenário para o filme. Isto é, objetos em miniatura contendo detalhes, e que sugerem como requisito habilidade de motricidade fina, foram confeccionados por este aluno, o que surpreendeu o grupo, o próprio aluno e as pessoas que convivem de forma mais próxima com ele, como sua família. Além dessa descoberta, a dificuldade de coordenação de movimentos dos membros superiores que caracterizam este sujeito foi compensada por atitudes de persistência, atenção e determinação, além de estratégias de apoio das mãos, encontradas pelo aluno para obter maior controle motor.

Por outro lado, a interação dos surdos em um ambiente de pessoas com outras necessidades especiais parece ter provocado neles conflitos a respeito de conceitos preconcebidos sobre essas outras pessoas e uma conseqüente mudança. Referimo-nos ao fato de que, antes de ingressarem ao projeto, interagiam predominantemente com surdos - na escola especial e associações de surdos que freqüentam. No projeto, que teve sete meses de duração, tiveram oportunidade de convívio próximo com colegas com paralisia cerebral e deficiência mental, além da equipe de professores (todos ouvintes).

Nessa interação, demonstraram curiosidade em relação à forma de falar do aluno com paralisia cerebral, que, por sua aparência, costuma sugerir incapacidade intelectual e embora não ouvissem os sons que ele emitia, percebiam a forma diferente de movimentação buço-facial na comunicação oral deste sujeito. Os comentários sobre sua percepção deste aluno, conforme aumentava o convívio entre o grupo, permitiram à equipe perceber a descoberta gradual da capacidade real do aluno e admiração em relação a esse potencial. No mesmo sentido, o convívio com ouvintes possibilitou aos surdos percebem que diferentemente do que costumavam pensar, pelas experiências de segregação que acumularam, tal categoria "ouvintes" não é homogênea, encontrando-se dentro dela pessoas que simpatizam com a cultura surda, que desejam se aproximar a eles e que são contra os preconceitos que outros ouvintes manifestam.

Inevitável e enriquecedor foi tomar conhecimento de realidades particulares até então tão distantes das nossas, através dos relatos dos 
participantes. Os alunos surdos, por exemplo, compartilharam suas vivências diárias de discriminação no ônibus, na rua, e em outros espaços sociais, devido à sua forma diferente de se expressar. Relataram ser comum que outras pessoas ou se refiram a eles pejorativamente de "macacos" ou "deficientes mentais". Relataram também sentimentos de frustração por não poder se comunicar com suas próprias famílias que não se apropriaram da Língua de Sinais.

Ainda sobre o grupo de alunos surdos no projeto, e provavelmente pelo fato destes terem horizontes mais estreitos em termos de vivências novas até então, seus comportamentos, reações à abertura desse "novo" impactou. O episódio do primeiro contato com outras pessoas via chat é um exemplo disso e o seguinte comentário de uma das alunas surdas "como é possível falar com alguém que não vejo e que está longe?" demonstra o fascínio e tentativa de compreender o universo virtual, desconhecido até então.

Ainda no chat, observou-se a preocupação dos alunos surdos em escrever corretamente o português, mesmo levando tempo considerável para decidir a forma de escrita correta.

Por outro lado, situações que exigiram posicionamento moral também surgiram durante o bate-papo virtual. Uma dupla de alunas surdas se viu "tentada" a dar uma informação diferente da realidade - uma delas queria dizer que eram mais velhas e estavam em uma série escolar superior. Esta aluna tentou ter a concordância de sua colega com quem trabalhava em dupla, quem por sua vez, se mostrou firmemente contra "mesmo se os outros não as viam nem ficariam sabendo.

Nessa mesma situação de interação síncrona (chat), foi interessante também perceber uma exclusão dos surdos por parte dos colegas-ouvintes. A inclusão dos alunos surdos no chat precisou da intervenção de um professormediador para que eles fossem considerados pelos demais. No entanto, após a intervenção, verificou-se um reconhecimento dos interlocutores virtuais ouvintes em relação aos surdos, que parece ter ocorrido ao conhecer melhor sua realidade de vida. Mais especificamente, quando ficaram sabendo do grande esforço destes para estudar, levando até algumas horas em suas viagens diárias para vir a Porto Alegre, pois somente na capital existe escola especial pública para essa população.

O resto do grupo também aprendeu com os surdos. Por exemplo, a aprendizagem de alguns sinais da Língua Brasileira de Sinais (LIBRAS), ocorreu de forma natural tanto por parte das professoras quanto dos colegas ouvintes com paralisia cerebral e deficiência mental. A este respeito cabe mencionar a jovem com deficiência mental, quem demonstrou maior interesse nessa língua chamando a atenção pela aprendizagem que realizou e pelas reações que provocou. Durante os encontros, esta abandonava a sua comunicação oral normal, passando a comunicar-se apenas em LIBRAS não apenas com os colegas surdos, mas inclusive com os demais participantes ouvintes. 


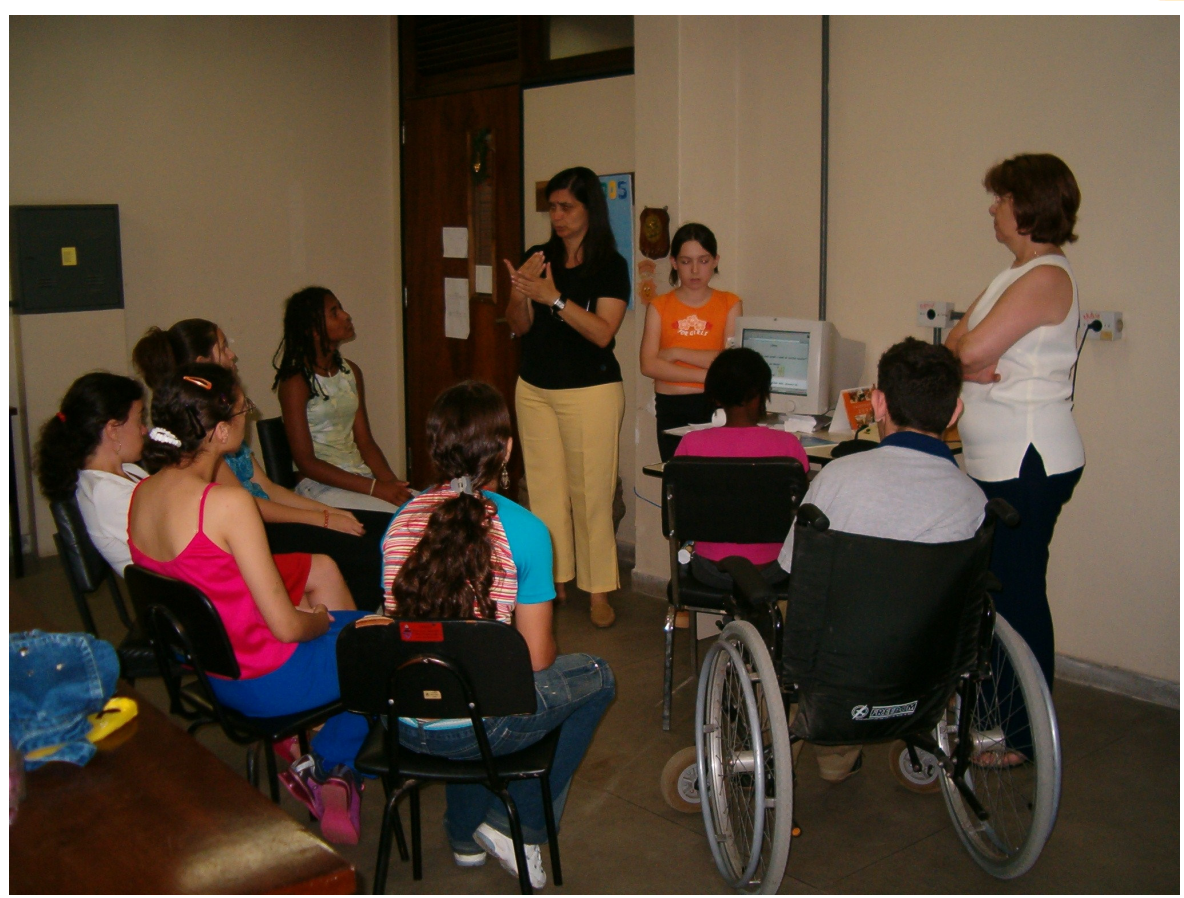

Figura 3- Participantes do Projeto com tradutora de LIBRAS.

\section{Reflexões sobre os aspectos observados}

Sobre os aspectos observados, estamos convencidos que tanto a descoberta de habilidades motoras quanto à criação de estratégias (resolução de problemas) por parte do aluno com paralisia cerebral, foram possíveis devido às atividades propostas aos alunos, ao ambiente criado e à mediação utilizada pela equipe de trabalho, à não definição a priori do que cada aluno poderia ou não fazer. Convém lembrar que a resolução de problemas é um processo psicológico superior importante, sob a ótica da teoria de desenvolvimento sócio-histórica de Vygostky (1987, 2000), Luria, Leontiev e outros estudiosos. A capacidade de síntese mostrada pelo mesmo aluno também se constitui em outro processo psicológico superior.

É no mínimo interessante ter consciência da complexidade envolvida na apropriação da Língua Brasileira de Sinais (LIBRAS), neste caso relacionado à jovem com deficiência mental. Isto é, tal aprendizagem corresponde à aprendizagem de uma língua estrangeira. A surpresa manifestada pela família, colegas e professores quanto a esta aquisição lingüista por parte desta aluna, pode ser entendida pelas baixas expectativas que se costumam ter sobre qualquer pessoa com deficiência mental. A este respeito apoiamo-nos em Ceccim (2004) que, ao abordar a segregação social e histórica de PNEEs no cenário mundial e brasileiro, considera ser a deficiência mental a que mais sofre tal estigma em relação às outras deficiências. Esse mesmo autor esclarece que ela (deficiência mental) carrega marcas de segregação e exclusão muito fortes, constituindo-se num "outro sobre o qual se fala, mas que não fala"' (pág. 30). 
Por sua vez, ao refletirmos sobre o menosprezo para com os surdos, comentado na seção anterior, e em relação à sua forma de comunicação e a sua língua, acreditamos deva-se ao fato da LIBRAS ser uma língua sinalizada e não- verbal, diferente da língua falada e dominante, e, portanto fadada a ser considerada socialmente como mais primitiva. A este respeito apoiamo-nos novamente em Ceccim (2004) que aponta para a tendência da sociedade em não acolher a diferença, em "normatizar" e em rotular como primitivo e/ou anormal, tudo que foge dessa norma.

Quanto à tendência dos surdos agruparem-se e interagirem preponderantemente com outros surdos, tal realidade, ao que parece, acaba por formar um tipo alternativo de "família" constituída por amigos surdos e professores das escolas de surdos, pessoas que "falam sua mesma língua" e, portanto os entendem. As famílias sangüíneas no caso dos surdos, quando não são capazes de se comunicarem em LIBRAS, não são as pessoas mais próximas como se esperaria ou costuma acontecer com os ouvintes. A este respeito, é interessante refletir sobre o profundo significado de reconhecer (ou não) a língua de uma pessoa. Basilier Terje, psiquiatra norueguês surdo, nos diz que:

Quando eu aceito a língua de outra pessoa, eu aceitei a pessoa... Quando eu rejeito a língua, eu rejeitei a pessoa porque a língua é parte de nós mesmos... Quando eu aceito a língua de sinais, eu aceito o surdo, e é importante ter sempre em mente que o surdo tem o direito de ser surdo. ${ }^{4}$

Ainda em relação aos surdos, e às constatações de exclusão no espaço de interação virtual (o chat) em que interagiram com colegas-ouvintes, convém lembrar que a escrita do português é justamente uma das maiores dificuldades que as pessoas surdas enfrentam. Por sua vez, em tais ambientes virtuais a forma de comunicação predominante é a linguagem escrita. Quem escreve mais lentamente e/ou com erros, pode ser segregado em algumas situações de interação. Nesse contexto, espera-se que os participantes sejam capazes de se expressarem por escrito de forma rápida e clara. Portanto, a "naturalidade" neste episódio de "exclusão virtual" dos surdos seria, no nosso entender, devido não ao fato de serem surdos, mas à dificuldade destes alunos em escrever rapidamente (digitar rapidamente) e corretamente como qualquer pessoa que esteja ingressando a esse mundo de interação on-line pode vir a vivenciar.

Por outro lado, convém também pensarmos sobre a possibilidade de utilizar pedagogicamente recursos de comunicação como estes (síncronos, mas preferencialmente, assíncronos pelo tempo maior que estes segundos oferecem para a elaboração da comunicação escrita). Poder-se-iam constituir em estratégias viáveis para os professores que trabalham com surdos e que costumam enfrentar dificuldades para motivá-los à escrita do Português, sua segunda língua. ${ }^{5}$ Assim, encontrar-se-iam envolvidos em situações reais de comunicação nas quais faria sentido escrever corretamente, uma vez que estaria presente o desejo de ser visto e incluído no processo da comunicação,

\footnotetext{
${ }^{4}$ http://www.menorahdeaf.com.br/perspectivasociocultural.htm

${ }^{5}$ No caso das pessoas surdas considera-se a LIBRAS como sua primeira língua e o Português, a segunda. V. $4 \mathrm{~N}^{\circ} 1$, Julho, 2006
} 
afastando-se de situações fictícias em que escrever representa mera atividade, fim em si mesma, e, portanto sem maior sentido para os alunos.

\section{Algumas Considerações e as Perspectivas do projeto}

Esperamos alcançar em longo prazo outras metas, como por exemplo, a construção e ampliação de parcerias a partir das quais as pessoas possam refletir sobre a aceitação recíproca e a inclusão dos "diferentes" na sociedade em geral e na educação em particular. A concretização da segunda etapa do projeto promete contribuir para tal meta,

Em suma, acreditamos no potencial da web como recurso que não somente influencia, mas que ajuda a criar 0 imaginário social, as representações sociais dominantes. Utiliza-la como recurso para mostrar as capacidades de pessoas com necessidades especiais, especialmente aquelas que envolvem o domínio de tecnologias de ponta, constitui-se, hoje em dia, em uma estratégia poderosa capaz de contribuir com uma sociedade mais inclusiva. Nesse contexto, habitar o ciberespaço com páginas que mostrem experiências já desenvolvidas como esta, ou seja, divulgando imagens reais sobre as capacidades de pessoas surdas, com limitações de locomoção, deficiência mental e outras "deficiências", é otimizar o poder de alcance que a web tem como recurso de informação e comunicação, categoria onde esta se enquadra. Significa como dissemos anteriormente, resgatar o papel social dessas tecnologias. Cabe, pois a nós profissionais, comprometidos e atuantes junto às pessoas com necessidades especiais trilharmos novos caminhos, criar novos ambientes de aprendizagem e principalmente continuar a acreditar na importância de propiciar experiências de descobertas das próprias potencialidades, habilidades, interesses.

\section{Bibliografia}

BEYER, H. O. Inclusão e Avaliação na Escola. Porto Alegre: Mediação, 2005.

CARVALHO, R. E. Removendo Barreiras para a Aprendizagem. Porto Alegre: Mediação, 2003.

CECCIM, R. B. Exclusão da alteridade: uma nota de imprensa a uma nota sobre a deficiência mental. In: SKLIAR,C. Educação e Exclusão. Porto Alegre: Mediação, 2004.

LURIA, A. R. Desenvolvimento cognitivo- seus fundamentos culturais e sociais. São Paulo: Ícone, 1990.

SKLIAR, C. Educação e Exclusão. Porto Alegre: Mediação, 2004. 
TIJIBOY, A. V. Um Olhar Sócio-Historico na Interação com Pessoas com necessidades Educacionais Especiais em Ambientes Digitais. In: Informática na Educação: Estudos Interdisciplinares. FRANCO Sergio (organizador), Porto Alegre: Editora da UFRGS, 2003.

VYGOTSKY, L. S. A Formação da mente. São Paulo: Martins fontes, 1984.

VYGOTSKY, L.S. EI Desarrollo de los Procesos Psicológicos Superiores. Barcelona: Crítica, 2000. 